\title{
How can I keep calm during self-isolation?
}

On top of the stress of work, there are now additional pressures to deal with at home, especially if you are self-isolating. Abi Rimmer asks experts how best to manage these

\section{Abi Rimmer}

The BMJ

\section{Kids can learn through play}

Adam Dobson, head of early years foundation stage at Thames View Infants School, Barking, says, "As an early years teacher, and a parent of a five year old, I've experienced the difficulty in trying to recreate the classroom at home.

"All children thrive on routine-it's the same every day in school. Share a daily schedule with your children and avoid sudden changes or surprises. Short bursts of more formal learning, such as spelling or writing, followed by planned play time will help children to get through the day. Consistent behaviour expectations, boundaries, and rules also help provide structure just as they would at school.

"A key thing to remember is that the unique atmosphere of school cannot be recreated at home. Young children, especially those in early years, spend a significant amount of time at school learning through play rather than working independently. At home, activities such as playing "shops," cooking, or gardening cover different aspects of learning, but also provide valuable practical experiences and inspiration for other learning. Most importantly, you, as the teacher, provide the language children need to share and express their ideas in their own drawing or writing.

"Most schools will have provided some form of home learning. The youngest children may not yet be able to write extensively or complete endless worksheets. There is, however, plenty of free content available online. Schools such as mine are also using platforms like Twitter to share these links, and make their own videos guiding children and parents through activities to do.

"A final thought would be to have fun and make the most of your time together. Teaching young children requires patience, and what is important is to foster a love of learning and a positive attitude to it. At school the most productive children can't wait to show adults what they've done-it will be the same at home too."

\section{Routine is key}

Jon Bailey, autonomous underwater vehicle operations engineer at the National Oceanography Centre, says, "As a former submarine weapons officer in the Royal Navy, I spent several weeks at a time in a steel tube underwater, hundreds of miles from home. These are my tips to keep your mood high during lockdown

"Life at sea is a clockwork pattern of shifts. Routine gives you direction and keeps the time flowing - so establish one early on, before low mood sets in. Set times for work, hobbies, meals, and so on. Write it down and stick to it. Don't lay about in your pyjamas—or at least have daytime pyjamas. Do at least 30 minutes exercise a day; it breaks up the day and can help lift your mood.

"Food at sea was pretty good; you could tell what day it was by the dinner menu. Food will be something to look forward to, so indulge your favourites.

"On patrol we had little contact with the real world and it was our shipmates who helped get us through. Keep in touch and build a 'crew' of supportive people. My work team has a daily coffee catch up on Zoom even if there's no work to discuss. If you cohabit then give everyone a private space or time. On a submarine your bunk was the only sacrosanct space and the respite was needed.

"Fight to keep perspective. It's a bad situation but, like all patrols, this one will end. Don't obsess over the news. Bring your world closer, focus on little things that you enjoy and make plans for the future. My partner is an emergency medicine doctor and my heart genuinely goes out to you all."

\section{Exercise is as a life saver}

Scarlett McNally, consultant orthopaedic surgeon and deputy director for the centre for perioperative care, says, "For those in household isolation or working from home, now is the time to get fit. Exercise helps mental and physical health, sleep, and immunity. It's particularly important for those in vulnerable, high risk groups, so encouraging aged parents, for example, as well as doing it yourself, can make a huge difference.

"Exercise guidance tells us that adults of all ages and disabilities should undertake a minimum of 150 minutes a week, with one hour a day for children. Any amount of exercise, however, makes a difference to mental and physical health.

"Results are rapid. Studies show fewer anaesthetic complications when preparing for cancer surgery with daily exercise for just three weeks. Resources such as those developed by the Centre for Perioperative Care ${ }^{1}$ can help you prepare for contracting covid-19. 
"The human psyche has to overcome inertia. Plan an exercise schedule, including mini-goals. Verbalise intentions. Involve all the family. Aim to start with 20 minutes per day of aerobic exercise.

"The Academy of Medical Royal Colleges' report, Exercise: the Miracle Cure, lists powerful effects on prevention and treatment of multiple common conditions. ${ }^{2}$ The post-pandemic NHS may not cope with more ill health from inactivity, including excess hip fractures, heart disease, diabetes, dependency, and mental ill health.

"Exercise is for now and the future, for us, our colleagues, families, and patients."

\section{Resist lethargy}

Paul Warrior, personal trainer, says, "Fitness and health are synonymous. Exercise is known for improving our physical state through developing metabolic pathways, supporting movement mechanics, and creating robustness in joints and vulnerable areas.

"Exercise is also a useful tool in improving our psychological wellbeing. It provides routine, a sense of accomplishment, releases stress, and shifts our focus onto our physical and mental state.

"Using a 12 minute exercise window we can expose the body to a dose of appropriate stimulus for that day's rotation through the metabolic pathways. For example, breaking the 12 minutes into short high intensity intervals can test the body's anaerobic systems.

"Alternatively, we can improve our aerobic, cardiovascular, and cardiac performance with longer, less intense intervals throughout the 12 minutes.

"Sessions can use simple movements such as push ups, sit ups, star jumps, lunges, and crawling. The priority is always to move in ways that support our daily functional needs. We suggest training a minimum of three to four times per week allowing five minutes either side to warm up and cool down.

"Stand up and move, resist lethargy, and embrace self-care. A fitter, healthier, and more focused you is a powerful tool and you matter."

\section{Useful websites for exercise tips}

www.fsem.ac.uk/staying-active-at-home

www.sportengland.org/stayinworkout/\#get_active_at_home

www.cpoc.org.uk/patients

You can find Paul Warrior's self-isolation workout plan for healthcare staff here: http://workingoutwellbeing.co.uk/wp-content/uploads/2020/03/VICTORY.pdf

1 Centre for Perioperative Care. www.cpoc.org.uk

2 Academy of Medical Royal Colleges. Exercise: the miracle cure and the role of the doctor in promoting it. 2015. www. aomrc.org.uk/reports-guidance/exercise-the-miracle-cure0215.

Published by the BMJ Publishing Group Limited. For permission to use (where not already granted under a licence) please go to http://group.bmj.com/group/rights-licensing/ permissions 